Humanur Bagli bagli@itu.edu.tr Istanbul Technical University
Blucher Design Proceedings Dezembro de 2014, Número 5, Volume

\title{
From Technical To Social: A Unique Case Of Design For Filigree Work In Mardin
}

This paper aims to demonstrate the ideas and studies derived from the project "Development of Silver Filigree Handcrafting in Mardin" held under the "Cultural Heritage Development Programme of the Gap Region".

The significant feature of this project is that it has been held under the leadership of Mardin Branch of the Association for Handicapped Persons. The continuation of tradition and formal interpretation of the existing cultural patterns is the main aim of the project. However, another aim of employing the handicapped people and teaching filigree craft to them added an overall value to the project in social responsibility manners and re-shaped the whole process of research and ideation. This feature of the project has influenced the design approaches as well. So, some technical interventions have had a decisive effect on design and production phase. Consideration of the handicapped people by suggesting the right technique for the right design in a sustainable understanding contributed to the originality of the whole scenario, together with outcomes of the project.

design, sustainability, handicapped, social responsibility, production technique

\section{Introduction}

This paper aims to demonstrate the ideas and studies derived from the project "Development of Silver Filigree Handcrafting in Mardin" (carried out by Mardin Branch of the Association for Handicapped Persons and European Union) held under the "Cultural Heritage Development Programme of the Gap Region".

Mardin is one of the oldest cities in Anatolia and a very important cultural center, where different religions and their unique architectural pieces come together in a very special context. The craft of Filigree Silverworks has also an important cultural role among the rich and diversified arts of Mardin. Nevertheless, the jewelry and other products made out of filigree craft are not enough to reflect this rich and diversified texture of the city. One of the reasons for this situation could be certain limitations in the investments to new approaches in the local area by interpreting and transferring technical and aesthetic aspects of innovative modern designs to the current filigree craft.

Filigree is a delicate kind of jewellery metalwork, made with tiny beads and twisted threads, or both, soldered together to create semi-transparent artistic patterns or motifs. In Mardin, especially in the old city of Midyat, filigree work has been produced since 15th Century, known as telkari (http://en.wikipedia.org/wiki/Filigree). 
In the formulation of project, two experts were assigned for the analysis and synthesis phases: one is an art historian and the other, designer. The art historian's role is to make a research on the history and culture of Mardin and surroundings and provide a report out of this data. The designer's role is to make use of the data provided by the art history report for new and innovative designs to reflect this cultural context. The brief given to the designer had an emphasis on focusing to mostly on the Cultural Heritage of Mardin in formulation of new designs. The designer was asked to get inspired from the architectural patterns of Mardin and make form-based designs out of the data extracted. Besides the art history report as the initial source of inspiration for design ideas and products, the research trips examining local, cultural and architectural premises, particularly silver ateliers and market research were helpful as a standing point to outcomes carried through the project.

Yet again, a significant feature of this project is that it has been held under the leadership of Mardin Branch of the Association for Handicapped Persons. The continuation of tradition is aimed by employing the handicapped persons and teaching filigree craft to them, which is overall adding value to the project in social responsibility manners. However, this feature of the project has been stated independent from the design processes and was not meant to influence the design approaches as well. In other words, the whole research, analysis and design phases of the project concentrated on the cultural and formal qualities of Mardin's architecture, not the limitations such as production of design pieces by the people employed in the workshop.

However, this is a very important point where the real and original contribution in design phase is formulated, in the processes of analysis and synthesis. That is consideration of the handicapped people by suggesting the right technique for the right design in a sustainable understanding contributed to the originality of the work itself. As it will be mentioned, some technical interventions have had a decisive effect on craftsmanship of the handicapped persons.

Another motivation for the uniqueness of the design research and implementation derives from the position of jewelry design or accessory design among other design categories. This category, as is known, as a branch of design, has an aesthetical aim. One could count millions of different design in the history of jewelry, because almost every shape can be transferred into design. For that reason, in the search of originality, the endless search of styling is not considered as an effective tool to make jewelry or accessory design anymore.

As Walker (2006) suggests, we need to transform design education and design practice and develop a new way of perceiving the notions of "good design" beyond appearance and aesthetics and seek for "real" social change by the responsibility that is shared among all agents related to design (Papanek, 1971).

\section{Process}

In scope of the research and design process under "Development of Filigree Silverworks in Mardin Project", at least ten different designs which obtain diverse qualities and functions were intended to be selected, applied and officially registered.

During the Project three main visits to "Mardin Branch of the Association for Handicapped Persons" - with a total of 20 days- were performed. Each visit consisted different phases of the Project. The first phase was held in 22-26 November 2006 for 5 days, the second 
phase was 4-13 January 2007 for 11 days, and the last phase took place in 25-28 January 2007 for 4 days.

From the beginning till the end, the process could be summarized under the following titles:

\title{
Research and Investigation Process:
}

1.Introduction to the Project Team and the first idea exchanges upon the Project (Project Coordinator, President of Mardin Branch of the Association for Handicapped Persons, Project Secretary, Filigree Craftsmen and participators)

2.Investigations upon the material and process relations in the atelier environment and the technical capabilities

3.Educational and technical trials upon the Filigree designs and techniques

4.Market Research in silverware stores and in antiquary shops in Mardin (models and prices)

5.Gathering Information and Photo Shooting

6.General Cultural Research

7.Evaluation of the Collected Data (Meetings with the Art Historian and investigating the "Final Report of Art History")

\section{Design Process}

\author{
1.Analysis \\ 2.Abstraction and Sketching \\ 3.Design \\ 4.Technical Trials and Modelling \\ 5.Feedbacks and Revisions \\ 6.Finalization
}

As understood from these headings, it was experienced firstly a detailed analysis, depending on research and observation, and a process of synthesis, depending on the exploration and variation of these data. However, these processes are not independent from each other and didn't follow a linear path. The designer experienced the communication and feedback between these processes in various ways making the whole process and the studies a rich one.

Along with the project, the designer had a close relationship with the possible users including the local people and the visitors of Mardin together with the students in the workshop and the producers of the project; writers and craftsman, so that the study didn't have an abstract character in its dynamics.

On the other hand, the study having not only on the cultural or technical data, but also a combination of them, made the study more multi-faceted. The cultural aspect of the study is dependent on the Art History Report and field studies and observations held by the designer. Moreover, practical studies performed with the workers and the master of silver in the Workshop of Filigree has helped develop the technical originality of the subject.

Apart from the classical production techniques, Silver Press Machine obtained for the project to the Workshop of Branch of the Association for Handicapped Persons, is very important to enhance the aspect of industrialization of the silverwork. The designer of the project has had the chance to exceed the classical understanding of design and production in the sense of finding only new patterns and forms. By the technical advantages of this machine, she had a chance to work on the products starting directly 
theme 4

technology strand 3

design and technology

from the potentials of it influencing the whole production line

\section{Outcomes}

The time the designer spent in the filigree workshop has helped her to understand the social relations as well as the production processes. The atmosphere was a very friendly one, where everybody likes to spend their times, whether productive or not. The reason why some people were mostly idle was that filigree production is highly craft-based and includes intricate work, which is independent from the people's degree of disability.

After learning the most basic steps of producing filigree craft, which are production of strings, flat pieces and filling; also basic shapes, designer started to develop new ideas of design.

One of the alternatives is illustrative in the sense of both stylistic and production points of view; that is based on the figure of Sahmaran. Sahmaran is a legendary creature that her head is in the shape of a woman and body is similar to a snake's with multiple feet. This figure is so important in the cultural climate of Mardin and it was not used as a figure in filigree designs in Mardin before.

The first sketches were based on the classical frame-filling technique with an abstraction of Sahmaran (Figure 1).

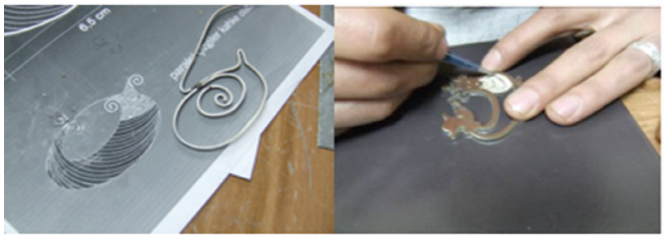

Figure 2.

The second alternative.
Figure 1.

Teh first sketches of Shamaran.

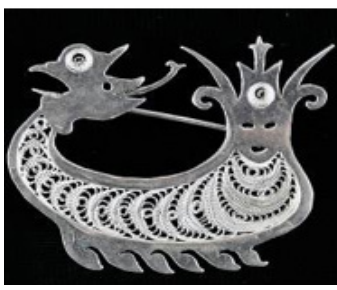

This figure was interesting and original, however the craftsmanship of the frame was so hard to make and also fill in with the technique of filigree. Also it was hard to recognize as a figure of Sahmaran because of the degree of abstraction, which is a disadvantage for a touristic object as a souvenir, because we learned that most of the tourists who visit Mardin prefer iconic shapes that looks like the figure of the original source.

The second alternative was the turning point where these two problems were solved by a simple design and production decision (Figure 2). In this alternative, instead of classical frame of string, a frame made out of cut-out planar silver was selected. This piece is planned to be produced by the Silver Press Machine in the workshop, which was not used effectively so far. So, it was easy to cut, also stiff as a frame, easy to fill and also easy to make intricate and complex shapes. So the designer had a chance to create a more Sahmaran-looking shape by the help of this technique. 
After this experience, the other design alternatives were developed with a similar approach and they constituted a brand-new set of designs, specialized for Mardin by the selection of shapes, also for handicapped people because they were much easier to produce than the classical techniques (Figure 3 ).
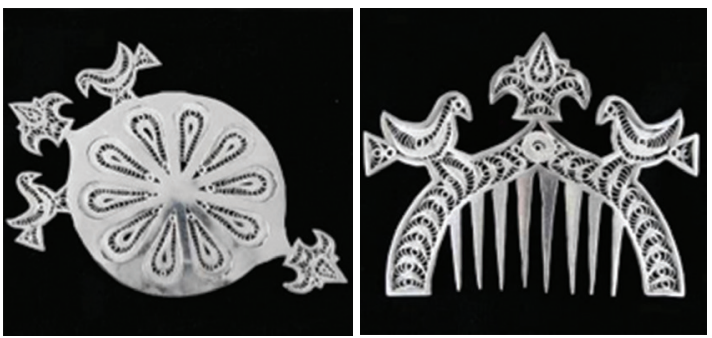

Figure 3 .

Some other examples of filigree designs with a new technique

\section{Results}

The project of "Development of Filigree Silverworks in Mardin" carried out by Mardin Branch of the Association for Handicapped Persons, can be regarded as an original contribution in the sense of the products as outcomes, together with the approach to the phases of analysis and synthesis .

Regarding the aspect of social responsibility in this project, consideration of the disabled by choosing the right technique for the right design in an industrial sense contributed to the originality of the work itself.

This makes us closer to how Martin (2009) defines the qualities of design thinking: "A person or organization instilled with that discipline is constantly seeking a fruitful balance between reliability and validity, between art and science, between intuition and analytics, and between exploration and exploitation (p.62)" So, this case presented here is a typical example of a story in which designer has a primary role in terms of design thinking which is not an exiled know-how about the formulation of the appearance qualities only, but to reconcile different aspects of a socially innovative process; research, analysis, observation and intervention in a positive sense.

\section{References}

Martin, Roger (2009). The Design of Business: Why Design Thinking is the Next Competitive Advantage, US, Harvard Business Press.

Papanek, Victor (1971). Design for the Real World: Human Ecology and Social Change, New York, Pantheon Books.

Walker, Stuart (2006). Sustainable by Design: Explorations in Theory and Practice, London, Earthscan 
